Aletria, Belo Horizonte, v. 29, n. 3, p. 249-265, 2019

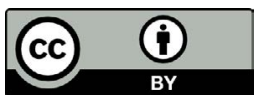

\title{
Notas para um conceito de imagem literária
}

\author{
Notes for a Concept of Literary Image
}

\author{
Roberto Duarte Santana Nascimento \\ Universidade Estadual de Campinas (Unicamp), Campinas, São Paulo / Brasil \\ rnascimen@gmail.com \\ Caio Russo \\ Universidade Estadual Paulista “Júlio de Mesquita Filho" (UNESP), Assis, São Paulo \\ / Brasil \\ nogueira.cvr@gmail.com
}

Resumo: Este ensaio se inscreve no âmbito de uma reflexão sobre o conceito de imagem literária enquanto fenômeno desvinculado do regime sensorial da visibilidade ou da alusão visível apenas, isto é, da imagem como ícone, semelhança, representação pictórica, reflexo. Nesse sentido, intentamos pensar a imagem literária a partir do seu movimento imanente, ou seja, como gesto que cria a condição material para a fabulação de objetos sensíveis - inauditos - sob forma de reorganização sintática e semântica do texto na vibração interna da plasticidade da palavra, no confronto do trabalho com a linguagem e na possibilidade infinita de reconexão das linhas que a tecem - numa possibilidade de imagem-textura - para além do eixo comunicativo e discursivo.

Palavras-chave: estética da literatura; imagem literária; teoria da imagem.

Abstract: This essay is part of a reflection on the concept of literary image as a phenomenon detached from the sensory regime of visibility or visible allusion only, that is, of the image as icon, similarity, pictorial representation, reflection. In this way, we intend to think of the literary image from its immanent movement, that is, as a gesture that creates the material condition for the fabulation of sensitive objects - unheard - in the form of a syntactic and semantic reorganization of the text in the internal vibration of the word plasticity, in the confrontation of the work with the language and in the 
infinite possibility of reconnecting the lines that weave it - in a possibility of imagetexture - beyond the communicative and discursive axis.

Keywords: aesthetics of literature; literary image; theory of image.

\section{Introdução: estética das imagens literárias}

Chamo de matéria o conjunto das imagens, e de percepção da matéria essas mesmas imagens relacionadas à ação possível de uma certa imagem determinada, meu corpo.

Henri Bergson

Neste ensaio na área de Teoria Literária, abordada como disciplina múltipla, perseguimos certa zona rarefeita nos Estudos Literários: a de um pensamento capaz de dar conta da produção sensível do literário, que se pretende vincular a uma Estética da Literatura por meio de um pensamento movente das imagens. ${ }^{1}$ Não se propondo como um pensamento prescritivo, delimitador da literatura e do literário, nosso artigo tenciona partir da concretude desse espaço artístico para se pensar o conjunto de sensações, buscando extrair da experiência do sensível literário algo como um pensamento do sensível, que leve em consideração certo campo do intuitivo que a arte esculpe, elabora e materialmente traça, mas não se revela imediatamente recuperável enquanto conceito. Parece-nos, de fato, que é a partir dessa dinâmica de proximidade e distanciamento entre dois diferentes regimes de pensamento de produção de sentido - o sensível e o conceitual - que a estética pode, de certo modo, elaborar teorias. ${ }^{2}$

1 “'...] na imagem o ser se desagrega: ele explode e, ao fazê-lo, mostra - mas por tão pouco tempo - do que é feito. A imagem não é imitação das coisas, mas o intervalo tornado visível, a linha de fratura entre as coisas [...] A imagem pode ser, ao mesmo tempo, material e psíquica, externa e interna, espacial e linguajeira, morfológica e informe, plástica e descontínua [...] espaço e desejo agem ali em conjunto, a arquitetura e o rito, a troca e a morte [...] tornado visível na própria linguagem, numa admirável sugestão sobre o caráter orgânico do limiar convocado pela 'figurabilidade' da palavra [...]" (DIDIHUBERMAN. Diante do tempo: História da arte e anacronismo das imagens, p. 126).

2 Sobre a divisão dos diferentes grandes modelos de pensamento (Filosofia, Arte e Ciência) além de Adorno, em Teoria estética, e Deleuze, ver a questão mais propriamente 
Uma vez colocada a necessidade de analisar essa diferença entre sensibilidade e conceito, será preciso dizer que o presente ensaio se inscreve no âmbito do questionamento e da tentativa de elaboração de certa reflexão sobre o conceito de imagem literária enquanto fenômeno desvinculado do regime sensorial da visibilidade, ou da alusão visível apenas, isto é, da imagem como ícone, semelhança, representação pictórica, ${ }^{3}$ reflexo. Nesse sentido, intentamos pensar a imagem literária a partir do seu movimento imanente, ou seja, como gesto ${ }^{4}$ que cria a condição material para a fabulação de objetos sensíveis - inauditos - sob forma de reorganização sintática e semântica do texto, na vibração interna da plasticidade da palavra, no confronto do trabalho com a linguagem e na possibilidade infinita de reconexão das linhas que a tecem para além do eixo meramente comunicativo-discursivo, o que significa dizer que:

[...] a imagem não é uma exclusividade do visível. Há um visível que não produz imagem, há imagens que estão todas em palavras. Mas o regime mais comum da imagem é aquele que põe em cena uma relação do dizível com o visível, uma relação que joga ao mesmo tempo com sua analogia e sua dessemelhança. Essa relação não exige de forma alguma que os dois eixos estejam materialmente presentes. O visível se deixa dispor em tropos significativos, a palavra exibe uma visibilidade que pode cegar. $^{5}$

É nesse passo movente, na imagem como gesto, que pensamos, por um lado, a hipótese de uma imagem-textura, acontecimento que emerge

relacionada entre estética e poiésis, regime sensível e regime conceitual: PAREYSON. Os problemas da estética.

${ }^{3}$ No que diz respeito às relação do texto com a imagem e, também, a pintura: "Poesia e pintura, texto e imagem através de sistemas de signos diversos e de meios específicos a cada um, compartilham uma das questões que estão no cerne da atividade artística: representar [...] em narrativas que recorrem ao pictural, delineia-se uma reflexão sobre o processo criativo e a escrita, sobre os limites entre imitação e criação [...]" (ARBEX. Poéticas do visível: uma breve introdução, p. 58).

${ }^{4}$ Para a compreensão da produção artística como gesto - sobretudo na pintura - e produção de pensamento da própria arte: MERLEAU-PONTY. $O$ olho e o espirito; seguido de, A linguagem indireta e as vozes do silêncio e $A$ dúvida de Cézanne.

${ }^{5}$ RANCIÈRE. O destino das imagens, p. 15-16. 
no trabalho escultórico do escritor na criação de espaços sensíveis na agrimensura do escrever, na passagem, conforme Rancière, do regime representativo ao regime estético da arte:

Essa transformação do visível em táctil e do figurativo em figura só se torna possível por um trabalho bem determinado das palavras do escritor. Para começar, é o modo díctico do enunciado, modo da presença manifestada, que, pelo jogo de uma literalização, nos mostra Chardin "despejando" os pratos, isto é, transformando a representação da mesa em um gesto de projeção que torna equivalentes os atos de espalhar a cor e pôr a mesa [...] Mas, ao mesmo tempo, eles embaralham sistematicamente a identidade dos objetos e as fronteiras entre os reinos. ${ }^{6}$

Neste sentido, embora se possa tentar identificar certo fenômeno comum a diversas obras e textos, a própria natureza do que estamos buscando obriga-nos a reconhecer também certa pluralidade. Por exemplo, em Tu não te moves de ti, de Hilda Hilst (2014), os saltos lição aprendida com Kierkegaard - da construção do monólogo interno num caráter paratático, ainda que sutis, compõem um tecido em que a intimidade não se perde no confessional, mas cria movimentos, gestos possíveis que vão se desfiando, ganhando contornos que têm seu sentido no próprio ritmo, movimento e contraste de atmosferas cotidianas:

Encosta a face educada na minha lívida cara, o roupão de linho tem a gola pesada de bordados, as mangas largas envolvem os pulsinhos finos, duas hastes presas às duas mãos inúteis, mas lava-se sim, encharca-se de óleos sim, tateia o ventre examina os dentes, o espelho de face dupla acusa um diminuto pelo no veludoso queixo, espio, vê, Tadeu, duro como um espinho, hoje marco hora no dermatologista, pega, vê se não é duro. Duro sim. Absurdo um pelo no meu queixo. Absurdo, Rute, existires junto a mim, eu junto à empresa, a empresa no mundo, o mundo nesse todo, um espaço de buracos negros e redondos corpos, cintilâncias, negruras, uma extrassístole outra vez e cada vez que me repenso e sempre que sofro sedução e emigro, disso sim eu gosto, de ser tomado, de ser seduzido

${ }^{6}$ RANCIÈRE. O destino das imagens, p. 91. 
como estou sendo agora pela vida. sedução. Imagine, arranco neste instante, olha como espeta a mão. Se eu falasse com a voz do mundo como falaria? ${ }^{7}$

No entanto, podemos igualmente citar Água viva (1998), de Clarice Lispector, que, apesar de se distanciar da narrativa tradicional, também se distancia de Hilda, e, só com alguma dificuldade, pode ser enquadrada na "forma" generalista de prosa-poética, pois contém um gesto de (e na) escritura que elabora uma imagem-textura singular, na tentativa saturada de encapsular o instante mesmo nesse passado que é próprio da escrita, tecendo, por isso, movimentos epifânicos, analogias gestuais com as outras artes - no sentido das correspondances baudelairianas.

Já Maria Tereza Horta, em Ambas as mãos sob o corpo (2014), se utiliza da ekphrasis não para descrever o corpo, mas sim para encarná-lo como imagem movente, torná-lo parte substancial de contato, superfície de encontro entre peles, através da atmosfera cambiante do dia a dia na linguagem, constituindo um espaço sensível de precisão única, que experiencia a multiplicidade das imagens do prazer em vez de identificá-lo:

Deixava-se escorregar e a água tépida entreabria-se à medida que o corpo deslizava aderindo a ela, os braços e as pernas flexíveis, o corpo lento, os olhos sem expressão presos na água verde, reflexo do verde-ácido da piscina [...] Um imenso minuto em que ela descansaria calma, frágil até, quase perdida, prestes a deixar-se escorregar mais, os lábios a aflorarem o tecido da água, os membros inertes, moles. ${ }^{8}$

No que se convencionou chamar de "prosa poética" - iminentemente moderna - há incontáveis texturas de imagens, atmosferas várias e elaborações rítmicas, que vão dos desníveis no eu que se perde na própria intimidade em Max Blecher ${ }^{9}$ ao delírio paisagístico em Bruno Schulz (2015), da amargura infantil da perda em Bartolomeu Campos de Queirós (2011) à polifonia de vozes dissonantes em Antônio Lobo

\footnotetext{
${ }^{7}$ HILST. Tu não te moves de ti, p. 21.

${ }^{8}$ HORTA. Ambas as mãos sob o corpo, p. 10-11.

9 "Ao fechar os olhos, o vento aplicava sobre meu rosto um outro rosto, mais frio, e, do lado de fora das pálpebras, eu sentia como se portasse uma máscara, a máscara da minha face em cujo interior fazia escuro e frio como o verso de uma máscara metálica de verdade [...] Em nenhum lugar e em nenhuma circunstância, nunca acontece coisa nenhuma no mundo" (BLECHER. Acontecimentos na irrealidade imediata, p. 102).
} 
Antunes (2009), de Virginia Woolf (2004) a Juan Rulfo (2005), texturas estas que arquitetam, cada uma em cada momento, um tecido de sensações em devir, algo como a elaboração de um quase pensamento imanente à escritura, aos cortes e aos confrontos com a linguagem.

Um delineamento mais consistente de uma Estética da literatura requer, portanto, o esforço de acompanhar a textura literária na tentativa de captar seus sentidos estéticos vários, junto com seu modelo de pensamento imanente à formatividade das imagens, antes mesmo dos significados referenciais mais imediatos:

É difícil para nós, parece-nos fútil seguir, por exemplo, o poeta $[. .$.$] que diz que a casa do passado está viva em$ sua cabeça. Logo traduzimos: o poeta quer simplesmente dizer que uma velha lembrança está guardada em sua memória. O excesso da imagem que gostaria de inverter as relações entre conteúdo e continente faz-nos recuar [...] Seríamos mais indulgentes se acompanhássemos as autoscopias da febre. Seguindo o labirinto das febres que corre em nosso corpo, explorando as "casas da febre", as dores que habitam um dente cariado, saberíamos que a imaginação localiza os tormentos e que faz e refaz anatomias imaginárias. ${ }^{10}$

\section{Imagens: afetos e sensações em movimento}

Pensar uma imagem criadora de sensação, ${ }^{11}$ em outras palavras como potencialidade de criação de afetos, ${ }^{12}$ através das linhas da costura literária, é condição sine qua non para estabelecermos a construção dos espaços da literatura, sua multiplicidade topológica como arquitetura, fabulação sensível, mobilidade do virtual, compreendendo que há um pensamento imanente ao fazer literário que não se dilui no entendimento,

\footnotetext{
${ }^{10}$ BACHELARD. A poética do espaço, p. 227.

${ }^{11}$ Pensamos a ideia de sensação aqui conforme conceitualização deleuziana, a saber, como intensificação da sensibilidade. Intensificação esta que se dá pelo encontro violento e não domesticado com o Fora. A respeito dessa ideia original de sensação, ver: DELEUZE. Francis Bacon: logique de la sensation. Ou então a edição traduzida: DELEUZE. Lógica da sensação.

${ }^{12} \mathrm{O}$ conceito de afeto é tomado, aqui, no sentido spinozista: alinhavar de linhas, forças, intenções, ver: SPINOZA. Ética.
} 
nem no lógico-discursivo. As imagens, como já havia notado Bergson, são espaços intensivos, ora:

[...] uma percepção é como uma partícula: uma percepção atual rodeia-se de uma nebulosidade de imagens virtuais que se distribuem sobre circuitos moventes cada vez mais distantes, cada vez mais amplos, que se fazem e se desfazem [...] As imagens virtuais são tão pouco separáveis do objeto atual quanto este daquelas. As imagens virtuais reagem portanto sobre o atual. Desse ponto de vista, elas medem, no conjunto dos círculos ou em cada círculo, um continuum, um spatium determinado em cada caso por um máximo de tempo pensável. ${ }^{13}$

É interessante notarmos como Deleuze, em diversos lugares de sua obra, reivindica ao pensamento algo como a imagem de um pensamento sem imagem, ou seja, querendo aludir com esta expressão à ideia de certa imagem do pensamento desvinculada de um regime estritamente visível, do ícone, ou mesmo do ídolo.

Assim, há momentos em que Deleuze procura conceber um "pensamento sem imagem", isto é, um pensamento que não seja mais presidido pela representação. Em outros momentos, no entanto, Deleuze fala na necessidade de uma "nova imagem do pensamento". Esta aparente contradição se desfaz quando consideramos que também a noção de imagem experimenta uma torção no pensamento deleuziano, uma vez que ela passa a operar como efeito ou produção direta do real e não mais como reposição simbólica de algo ausente. ${ }^{14}$

Romper com o olhar é lacerar, de certo modo, com uma longa tradição ocidental que tem no olho o píncaro do órgão do poder - já denunciado por Bataille (2003) em sua História do olho e, não à toa, reiterado no conceito de panóptico foucaultiano como instrumento de ordem, vigilância e controle.

Quanto à imagem literária, é válido a retomada do ponto de vista filológico que chama a atenção para a origem latina da palavra

${ }^{13}$ DELEUZE. O atual e o virtual, p. 51.

${ }^{14}$ NASCIMENTO. Teoria dos signos no pensamento de Gilles Deleuze, p. 17. 
texto enquanto tecido. Benjamin (1987) explora este caminho para falar da poética proustiana, compreendendo a não visualidade das imagens literárias elaboradas pelo escritor francês, e seguindo por este aspecto, $\mathrm{o}$ próprio traço deixado por Proust na elaboração dos espaços erigidos por sua escritura, quando ele reivindica, claramente, a produção do sensível para literatura, como forma de ultrapassar certo tipo de realismo:

[...] a engenhosidade do primeiro romancista consistiu em compreender que, no aparelho das nossas emoções, sendo a imagem o único elemento essencial, a simplificação que consistiria em suprimir pura e simplesmente as personagens reais seria um aperfeiçoamento decisivo. Um ser real, por mais profundamente que simpatizemos com ele, em grande parte só o percebemos através dos sentidos, isto é, permanece opaco para nós, oferece um peso morto que nossa sensibilidade não consegue erguer..$^{15}$

A imagem literária, no entanto, não é produzida apenas como parte de uma alusão do visível, é também o gesto que imprime um ritmo específico à linguagem criando um espaço sensível próprio da escritura “[...] na qual os momentos da reminiscência, não mais isoladamente, como imagens, mas informes, não-visuais, indefinidos e densos, anunciam-nos um todo". ${ }^{16}$ É nesse passo movente, na imagem como cegueira háptica que pensamos a hipótese de uma imagem-textura, acontecimento que emerge no trabalho escultórico do escritor na criação de espaços sensíveis na agrimensura do escrever, notório nessa passagem do regime representativo ao regime estético da arte.

Pensar uma imagem criadora de sensação, potencialidade de afecção, através das linhas da costura literária, é condição sine qua non para estabelecermos a construção dos espaços da literatura, sua multiplicidade topológica como arquitetura, fabulação sensível, mobilidade do virtual, compreendendo que há um pensamento imanente ao fazer literário que não se dilui no entendimento, nem no lógico-discursivo.

Também amplamente presente na constituição de imagem proposta por Jean-Luc Nancy (2002), através da separação espacial e da elaboração de um corpus, no pensamento da sensação como território de

\footnotetext{
${ }^{15}$ PROUST. Em busca do tempo perdido: No caminho de Swann, p. 92.

${ }^{16}$ BENJAMIN. Magia e técnica, arte e política: ensaios sobre literatura e história da cultura, p. 49.
} 
intensidades em Deleuze \& Guattari (1997), como movimento do tempo - a partir da leitura de Bergson mas não apenas - de Didi-Huberman $(2003 ; 2004 ; 2012)$ como passagem do visual ao háptico no território político que o sentir inaugura em Rancière (2009), como transfiguração da linguagem à imagem em Blanchot (1987), passagem para uma noção de imagem literária no sentido de pensar a diferença e a radicalidade do distinto que se cristaliza um átimo na imagem, contendo nessa negação, que não se polariza ou se resolve na síntese dialética, mas se estende nesse espaço não-teleológico que, inconclusivo, não perde por isso sua força de expressão; é falarmos de certa abertura para pluralidade do distinto, a imagem literária como epicentro do distinto, do que escapa ao discurso, às estruturas da linguagem, da diferença que traz consigo o halo teológico do sagrado, já que:

A imagem é uma coisa que não é a coisa: essencialmente se distingue dela $[\ldots]$ o que se distingue essencialmente da coisa é também a força, ou energia, movimentação, intensidade. Foi sempre o "sagrado" uma força, inclusive uma violência [...] por um traço distintivo a imagem é dada (imagem inteira ou a imagem indicando alguma forma) e que, deveras, a imagem dá, é, em princípio, uma força, uma intensidade, que é, sobretudo, a força de sua distinção. ${ }^{17}$

Nesse sentido, é necessário pensar a especificidade da imagem literária como movimento, possibilidade de criação do tecido sensível, reorganização do virtual, transitividade de afetos - para além da comunicação dos enunciados, interpretação ou identificação dos temas, discursos e estrito domínio da linguística. Por outro lado, não significa, de nenhum modo, lançar mão de uma nova metodologia identificadora, mas sim acompanhar o movimento da textura das imagens na elaboração da ipseidade de cada corte, ritmo e performance do texto, o que não significa, também, descartar a possibilidade de representação da literatura, da criação e veiculação discursiva, mas sim pensarmos a elaboração do pensamento sensível que se dá naquilo que Proust chamou de criação de uma "língua estrangeira" a partir da escritura literária, a dinâmica do gesto, da composição de espaço sensível, e não apenas do tema e do caráter comunicacional.

${ }^{17}$ NANCY. La imagem - Lo distinto, p. 11, tradução nossa. 


\section{Textura das imagens}

Mais do que uma teoria literária, "se for suficiente, como repetiu Deleuze, criar verdadeiros conceitos para iniciar uma obra filosófica, então o neutro é, com dois ou três outros como a amizade, o desastre ou a comunidade, aquilo que nos permite distinguir uma filosofia blanchotiana". ${ }^{18}$ Ao lado dos conceitos destacados, podemos colocar o de imagem, o de Fora, a noite, solidão, entre outros, que permitirão a Blanchot estabelecer o "espaço literário" como "[...] passagem de uma concepção clássica da literatura como 'revelação' a uma concepção moderna de escritura como "contestação"". ${ }^{19}$ Reivindicar uma filosofia blanchotiana é, sobretudo, falar da possibilidade de uma estética literária, de um novo posicionamento a partir - e não sobre - da textura literária.

Além do emblemático trecho sobre $A$ imagem $^{20}$ num tópico e $A s$ duas versões do imaginário ${ }^{21}$ da obra $O$ espaço literário (1987), foi uma longa nota de rodapé que nos chamou a atenção para o questionamento acerca da plasticidade do conceito de imagem literária quando pensada no gesto da escritura. Transcrevemos parte da nota de onde retiramos diversas questões que já nos inquietavam quanto à História da Arte, à Arte Moderna e à Estética, em intercâmbio com a especificidade da imagem na literatura:

O poema, pelo contrário, tem a particularidade de que nada nele constitui imagem. Por conseguinte, cumpre exprimir de outro modo o que procuramos: Será que a própria linguagem não se torna, na literatura, imagem inteira, não uma linguagem que conteria imagens o colocaria a realidade em figura, mas que seria a sua própria imagem, imagem da linguagem - e não uma linguagem figurada - ou ainda a linguagem imaginária, linguagem que ninguém fala, ou seja, que se fala a partir de sua própria ausência, tal como a imagem aparece sobre a ausência da coisa, linguagem que se dirige também à sombra dos acontecimentos, não à sua realidade, e pelo fato de que as palavras os exprimem não são signos mas imagens, imagens de palavras e

\footnotetext{
${ }^{18}$ BIDENT. Les mouvements du neutre, p. 13, tradução nossa, grifo nosso..

${ }^{19}$ BIDENT. Les mouvements du neutre, p. 25-26, tradução nossa.

${ }^{20}$ BLANCHOT. O espaço literário, p. 22-24.

${ }^{21}$ BLANCHOT. O espaço literário, p. 255-256.
} 
palavras onde as coisas se fazem imagem? [...] Segundo a análise comum, a imagem vem depois do objeto; ela é a sua sequência; nós vemos, depois imaginamos. Após o objeto, vem a imagem. "Após" parece indicar uma relação de subordinação. Nós falamos realmente, depois falamos imaginariamente, ou imaginamo-nos falando? A fala poética não seria senão o decalque, a sombra debilitada, a transposição, num espaço em que se atenuam as exigências de eficácia da única língua falante? Mas talvez a análise comum se equivoque. Talvez antes de ir mais longe, cumpre indagar: Mas o que é a imagem?22

Nessa admirável nota, Blanchot antecipa a crítica deleuziana ao decalque, à rostidade que engole e sobrecodifica qualquer possibilidade de corpo, à relação de causalidade entre objeto e aparência, sujeito e objeto, ente e imagem; indicando uma noção de imagem que seja fabulação de imagens, produção de imagens, dando autonomia ao sensível frente à sensação, o percepto à percepção, demonstrando que a imagem desliza no movimento para o Fora, é radicalmente imanente ao mundo literário.

A passagem da palavra à imagem, no sentido do enunciado comunicacional ao sentido imanente à criação de um espaço afetivo, desfaz a relação de causalidade que condiciona a imagem a não ser mais do que simulacro a ser atravessado, como a metáfora - certa procura por traduzir o que se esconde por detrás da pele do tecido textual - quando é nele, nesse mesmo tecido, que a linguagem pode se tornar acontecimento, como se o texto literário não parasse de se desviar de seu significado, configurandose mais como um lapso: a imagem literária é menos a possibilidade de nos dar a ver do que uma afirmação da sua própria cegueira constitutiva.

Compreendemos que a escritura, a imagem enquanto espaço de sensações e afetos, tem seu lugar na dinâmica do gesto. Performativa é parte da vibração que consolida uma atmosfera específica de cada texto em sua tonalidade, não sendo nem simulacro, nem representação ou síntese. À beira dos acontecimentos, seriam mais como:

Um ato e não uma coisa: um gesto - interminavelmente prolongado, variado, coreografado - e não uma síntese. Uma imprevisível epidemia de semelhanças impossíveis de serem reunidas e não uma previsível sucessão de

${ }^{22}$ BLANCHOT. O espaço literário, p. 25. 
aspectos congruentes. Um conhecer, não um reconhecer. Para tocar esse "meio absoluto, ali onde a coisa volta a ser imagem", para entrar nesse lugar e nesse tempo "em que a fascinação ameaça", não era preciso nada menos do que correr o risco de romper a Einigung, a unidade ou o arranjo do próprio pensamento. ${ }^{23}$

Talvez seja possível, a partir do conceito de imagem, reivindicar uma estética da literatura que conceba o fazer literário na sua materialidade, como imagem-textura, radicalizando a proposta de um espaço literário em sua imanência e esculpindo um conceito de imagem que pense o objeto literário - que seja produção de pensamento do literário -, como espaço de afetos, criação de atmosferas, arquitetura de sensações já imbuídas de sentido, materialidade.

\section{Imagens do Fora: desfazer o Eu}

Para Blanchot a solidão do escritor é algo de mais essencial, parte constitutiva de um trabalho que é inteiramente isento de finalidade, já começado pelo meio, em que falseamos os pontos de chegada e as conclusões, que têm por determinação seu caráter indeterminado. A obra literária não pode ser concluída porque não começou ainda.

Em plena consonância com Ser e Tempo (2009), Blanchot afirma: "Aquele que vive na dependência da obra, seja para escrevê-la, seja para lê-la, pertence à solidão do que só a palavra ser exprime: a palavra que a linguagem abriga dissimulando-a ou faz aparecer quando se oculta no vazio silencioso da obra." 24

A procura pelo ser desvelado do ente, para além da reificação, da noção de eidos ou ousia (no esteio de Heidegger), encontra em Blanchot um lugar privilegiado: é necessário deixar com que a obra instaure o seu lugar mesmo, interminável, inconcluso, em que tanto o escritor como o leitor se desfazem. Não há como estabelecer nenhum Eu do cogito sem questionar a res cogitam. Os traços de uma arquitetura da existência passam necessariamente pelo Dasein, que antecede e funda as relações existenciais no mundo antecipando as relações intelectivas.

${ }^{23}$ DIDI-HUBERMAN. De semelhança em semelhança, p. 50.

${ }^{24}$ BLANCHOT. O espaço literário, p 14, grifo nosso. 
Olhando rapidamente, a proposta de um espaço literário pareceria simples desdobramento do conceito heideggeriano de ser-no-mundo aplicado ao objeto literário, marcado pelo nada como condição da existência própria da escritura:

O Eu solitário vê-se separado, mas já não é capaz de reconhecer nessa separação a condição do seu poder, já não é capaz de fazer dele o meio da atividade e do trabalho, a expressão e a verdade que fundamentam toda comunicação exterior. Sem dúvida, essa última experiência é a que se relaciona geralmente com o abalo da angústia. $\mathrm{O}$ homem adquire então consciência de si mesmo como separado, ausente do ser, adquire consciência de que recebe sua essência do não-ser. ${ }^{25}$

Dessa comunicação exterior o Eu se vê participante, incluído no cotidiano, parte da palavra falante que naturaliza e substitui a relação do homem com o que o circunda, ora apagando, ora mascarando a própria ausência fundamental em que a linguagem está assentada, desligando-o do ser e reificando a comunicação num processo de substituição tecnificante. O passo além de Heidegger, a partir de Blanchot, está no desenvolvimento de uma teoria do Fora, que não se confunde com o exterior, entendendo o imaginário e seu instaurar - topoi da literatura - como lugar em que todo Eu se desfaz, se transfigura em um ele. Esse esboroar do Eu no seu fluir imaginativo (processo já antevisto por Kierkegaard) convida o pensamento a se des-subjetivar, insistindo na existência de um im-pessoal em que os afetos são transitivos e não apenas comunicativos, fora de nós.

Não há como pensarmos o conceito de imagem literária sem nos defrontarmos com o Fora. Dito que o Fora não é o exterior, simplesmente, o que dele poderíamos então dizer? O Fora é como o canto das sereias na Odisseia, esse profundo estranhamento de um lugar inatingível em que o pensamento se vê excluído e, justamente por isso, se fascina pela própria ignorância e impossibilidade, exilando-se para além dos próprios círculos do Dentro, os limites de onde ele pode pisar, de onde ele pode pensar:

Não devemos esquecer que esse canto se destinava a navegadores, homens do risco e do movimento ousado, e era também ele uma navegação: era uma distância, e o que

${ }^{25}$ BLANCHOT. O espaço literário, p. 254, grifo nosso. 
revelava era a possibilidade de percorrer essa distância, de fazer, do canto, o movimento em direção ao canto, e desse movimento, a expressão do maior desejo. ${ }^{26}$

Ulisses não pode habitar o Fora ou caminhar até o exílio porque se amarrou ao mastro, usou da própria astúcia para "ouvir" o canto das sereias em segurança, esquecendo que a escuta mesma do canto exigiria o gesto de lançar-se, o salto (kierkegaardiano) no in-definido. Ouvir o canto das sereias e fazer essa caminhada até o Fora - que, aliás, já é o próprio Fora - pediria a Ulisses fugir das certezas intelectivas em que estava enredado, pediria um passo rumo à Noite.

De modo algum o Fora é um lugar no qual se chega, um território estável. Sua mobilidade impede a cristalização de qualquer fixidez, é o movimento mesmo de ir ao Fora que constitui a imagem do Fora. Contrariamente algumas interpretações, o Fora não nos parece o oposto dialético do Dentro, é uma diferença, uma perversão negativa que se desvia do que está posto, avesso também à positivação, a imagem do Fora acontece no neutro.

É nesse espaço transitivo que a imagem literária pode se mover, flutuante, desligada do tropos linguístico (como metáfora, metonímia etc.) e fazendo da própria linguagem a vibração de um esculpir intensivo, força de afetos que sacrifica a comunicação, o ruído do falar cotidiano, na abertura de um nunca-antes. A imagem-textura pode ser vista, portanto, como um alinhavar ininterrupto, um corpo em movimento em que os afetos transitam, delimitando um espaço sensível virtual, em que os gestos sensíveis se inscrevem na escritura como acontecimento em devir.

\section{Referências}

ADORNO, T. W. Teoria estética. Tradução de Artur Mourão. Lisboa: Edições 70, 2008.

ANTUNES, A. L. Que cavalos são aqueles que fazem sombra no mar? Alfragide: D. Quixote, 2009.

${ }^{26}$ BLANCHOT. O livro por vir, p. 4. 
ARBEX, M. Poéticas do visível: uma breve introdução. In: (org.). Poéticas do visível: ensaios sobre a escrita e a imagem. Belo Horizonte: Programa de Pós-graduação em Letras: Estudos Literários: Faculdade de Letras da UFMG, 2006.

BACHELARD, G. A poética do espaço. Tradução de Antônio de Pádua Danesi. São Paulo: Martins Fontes, 1988.

BATAILLE, G. História do olho. Tradução de Eliane Robert Moraes. São Paulo: Cosac Naify, 2003.

BENJAMIN, W. Magia e técnica, arte e política: ensaios sobre literatura e história da cultura. Tradução de Sérgio Paulo Rouanet. São Paulo: Brasiliense; 1987.

BIDENT, C. Les mouvements du neutre. Alea: Estudos Neolatinos, Rio de Janeiro, v. 12, n. 1, p. 13-33, jan. 2010. Doi: https://doi.org/10.1590/ S1517-106X2010000100002.

BLANCHOT, M. O espaço literário. Tradução de Álvaro Cabral. Rio de Janeiro: Rocco, 1987.

BLANCHOT, M. O livro por vir. Tradução de Leyla Perrone-Moisés. São Paulo: Martins Fontes, 2005.

BLECHER, M. Acontecimentos na irrealidade imediata. Tradução de Fernando Klabin. São Paulo: Cosac Naify, 2013.

DELEUZE, G. Francis Bacon: logique de la sensation. Paris: Éditions de la Différence, 1981. 2 t.

DELEUZE, G. Lógica da sensação. Tradução de Roberto Machado (coord.). Rio de Janeiro: Jorge Zahar, 2007.

DELEUZE, G. O atual e o virtual. In: ALLIEZ, É. Deleuze filosofia virtual. Tradução de Heloisa B. S. Rocha. São Paulo: Editora 34, 1996. p. 47-58.

DELEUZE, G; GUATTARI, F. O que é a filosofia? Tradução de Bento Prado Jr. e Alberto Alonso Muñoz. São Paulo: Editora 34, 1997.

DIDI-HUBERMAN, G. A imanência estética. Tradução de Marcelo Jacques de Moraes. Alea: Estudos Neolatinos, Rio de Janeiro, v. 5, n. 1, p. 118-147, jul. 2003. Doi: https://doi.org/10.1590/S1517106X2003000100009. 
DIDI-HUBERMAN, G. De semelhança em semelhança. Tradução de Maria José Werner Salles. Alea: Estudos Neolatinos, Rio de Janeiro, v. 13, n. 1, p. 25-51, jun. 2011. Doi: http://dx.doi.org/10.1590/S1517106X2011000100003.

DIDI-HUBERMAN, G. Diante do tempo: História da arte e anacronismo das imagens. Tradução de Vera Casa Nova e Márcia Arbex. Belo Horizonte: Editora UFMG, 2015.

DIDI-HUBERMAN, G. L'image est le mouvant. Intermédialités: histoire et théorie des arts, des lettres et des techniques. Intermédialités: Histoire et Théorie des Arts, des Lettres et des Techniques, Montréal, n. 3, p. 1130, 2004. Doi: https://doi.org/10.7202/1005466ar.

DIDI-HUBERMAN, G. Quando as imagens tocam o Real. Tradução de Patrícia Carmello e Vera Casa Nova. Pós, Belo Horizonte, v. 2, n. 4, p. 204-219, nov. 2012.

HEIDEGGER, M. Ser e tempo. Tradução de Márcia Sá Cavalcante. Schuback. Petrópolis: Editora Vozes, 2006.

HILST, H. Tu não te moves de ti. São Paulo: Editora Globo, 2014.

HORTA, M. T. Ambas as mãos sob o corpo. Lisboa: Editora D. Quixote, 2014.

LISPECTOR, C. Água viva. Rio de Janeiro: Rocco, 1998.

MERLEAU-PONTY, M. O olho e o espírito; seguido de, A linguagem indireta e as vozes do silêncio e $A$ dúvida de Cézanne. Tradução de Paulo Neves e Maria Ermantina Galvão Gomes Pereira. São Paulo: Cosac Naify, 2004.

NANCY, J-L. La imagem - Lo distinto. Tradução de Moisés Barroso Ramos. Laguna: Revista de Filosofía, San Cristóbal de La Laguna, Espanha, n. 11, p. 9-22, sept. 2002.

NASCIMENTO, R. D. S. Teoria dos signos no pensamento de Gilles Deleuze. 2012. Tese (Doutorado em Filosofia) - Instituto de Filosofia e Ciências Humanas, UNICAMP, Campinas, 2012.

PAREYSON, L. Os problemas da estética. Tradução de Helena Nery Garcez. São Paulo: Martins Fontes, 2001. 
PROUST, M. Em busca do tempo perdido: No caminho de Swann. Tradução de Mário Quintana. São Paulo: Editora Globo, 2006.

QUEIRÓS, B. C. Vermelho amargo. São Paulo: Cosac Naify, 2011.

RANCIÈRE, J. A partilha do sensível. Tradução de Mônica Costa Netto. São Paulo: Editora 34, 2009.

RANCIÈRE, J. O destino das imagens. Tradução de Mônica Costa Netto. Rio de Janeiro: Contraponto, 2012.

RULFO, J. Pedro Páramo. Madrid: Catedra, 2005.

SCHULZ, B. Ficção completa. Tradução de Henryk Siewierski. São Paulo: Cosac Naify, 2015.

SPINOZA, B. Ética. Tradução de Tomaz Tadeu. Belo Horizonte: Editora Autêntica, 2009.

WOOLF, V. As ondas. Tradução de Lya Luft. Rio de Janeiro: Nova Fronteira, 2004. 